ISSN : $2450-766 X$

\title{
MENGEFISIENSIKAN PENGGUNAAN ENERGI LISTRIK : STUDI KASUS PADA MODEL ALIRAN PANAS PADA WATER COOKER (PEMANAS AIR ELEKTRIK)
}

\author{
S. Husnah ${ }^{1}$, A. I. Jaya ${ }^{2}$, dan R. Ratianingsih ${ }^{3}$ \\ 1,2,3 Program Studi Matematika Jurusan Matematika FMIPA Universitas Tadulako \\ Jalan Soekarno-Hatta Km. 09 Tondo, Palu 94118, Indonesia. \\ 1husnahshy1507@gmail.com, 2,3ratianingsih@yahoo.com
}

\begin{abstract}
Water cooker is one of the households that often used in everyday life. Water cooker in general use of electricity by the use of the heating elements for heating water. The device altering electrical energy to heat. A model of the hot flow of water cooker is lowered by look at it consists of two components namely water and house. In this research determined the time effectively to turn off water cooker to the use of electric energy more efficiently. By doing the observation in analytic on the second component obtained the time effectively to turn off water cooker is 15 minutes.
\end{abstract}

Keywords : : Effective Time, The Analytic Method, Water Cooker

\section{ABSTRAK}

Pemanas air elektrik merupakan salah satu alat rumah tangga yang sering dipakai dalam kehidupan sehari-hari. Pemanas air elektrik pada umumnya mengunakan listrik dengan penggunaan elemen pemanas untuk memanaskan air. Alat tersebut mengubah energi listrik menjadi panas. Model aliran panas dari pemanas air elektrik diturunkan dengan memandangnya terdiri atas dua komponen yaitu air dan wadah. Dalam penelitian ini ditentukan waktu yang efektif untuk mematikan pemanas air elektrik agar penggunaan energi listrik lebih efisien. Dengan melakukan pengamatan secara analitik pada kedua komponen diperoleh waktu yang efektif untuk mematikan pemanas air elektrik adalah 15 menit.

Kata Kunci $\quad$ : Metode Analitik, Pemanas Air Elektrik, Waktu Efektif

\section{PENDAHULUAN}

\subsection{Latar Belakang}

Upaya mengefisiensikan energi listrik merupakan hal yang penting dilakukan. Hal ini sangat membantu program pemerintah dalam upaya menghemat energi. Efisiensi energi 
listrik dapat dilakukan dalam wujud yang sederhana, salah satunya adalah dengan pengaturan penggunaan water cooker (pemanas air elektrik).

Pemanas air elektrik merupakan salah satu alat rumah tangga yang sering dipakai dalam kehidupan sehari-hari. Dalam penggunaanya pemborosan energi listrik sering dilakukan secara tidak sadar. Pada saat memanaskan air, biasanya aliran energi listrik dimatikan setelah air yang direbus mencapai titik didih. Tanpa disadari sikap ini merupakan pemborosan. Kita dapat melakukan efisiensi dengan menghentikan aliran listrik sebelum suhu air mencapai titik didih tersebut. Hal ini disebabkan meskipun ketika air dipanaskan air dan wadah pada mulanya bersuhu sama, namun setelah air mencapai titik didih suhu wadah menjadi lebih tinggi dibandingkan dengan suhu air. Fenomena ini disebabkan wadah memiliki kapasitas panas yang lebih tinggi dibandingkan dengan air. Fenomena perbedaan kapasitas panas yang mengakibatkan terjadiya perbedaan suhu ini dapat digunakan untuk menghemat energi listrik.

Suhu wadah yang lebih tinggi dibandingkan dengan suhu air memungkinkan untuk dialirkannya energi panas yang terkandung di dalamnya untuk menaikkan suhu air hingga mencapai titik didihnya. Dengan cara ini waktu yang digunakan untuk memanaskan air menjadi lebih singkat. Model matematika yang mempresentasikan fenomena perbedaan suhu wadah dan air telah dibahas dalam Workshop on Mathematical Modelling of Physical Phenomena yang diselenggarakan oleh Program Studi Matematika FMIPA UNTAD 23 - 26 April 2013.

\subsection{Rumusan Masalah}

Rumusan masalah dalam penelitian ini adalah bagaimana waktu efektif untuk mematikan pemanas air elektrik agar penggunaan energi listrik lebih efisien?

\subsection{Tujuan}

Tujuan penelitian ini adalah menentukan waktu efektif untuk mematikan pemanas air elektrik agar penggunaan energi listrik lebih efisien.

\subsection{Manfaat Penelitian}

Adapun Manfaat yang dapat diberikan pada penelitian ini adalah:

1. Meningkatkan pemahaman tentang model aliran panas

2. Membantu mengefisienkan penggunaan energi listrik

3. Secara umum untuk mengembangkan ilmu matematika, khususnya pada bidang matematika terapan 
4. Memberikan dampak yang positif bagi perkembangan penelitian multidisiplin ilmu di Indonesia, khususnya Matematika dan Fisika.

\subsection{Batasan Masalah}

Batasan masalah yang digunakan dalam penelitian ini adalah:

1. Model aliran panas yang digunakan diambil dari model yang diberikan dalam kegiatan Workshop on Mathematical Modelling of Physical Phenomena yang diselenggarakan oleh program studi Matematika FMIPA UNTAD. Model tersebut dinyatakan sebagai berikut :

$C_{1} \frac{d u_{1}}{d t}=-q$

$C_{2} \frac{d u_{2}}{d t}=q$

2. Nilai parameter yang terdapat dalam model diperoleh dari hasil eksperimen fisika sesuai ketentuan, yaitu :

$c_{1}=1 \frac{\mathrm{kal}}{\mathrm{gr}^{\circ} \mathrm{C}}$

$c_{2}=0.21 \frac{\mathrm{kal}}{\mathrm{gr}^{\circ} \mathrm{C}}$

3. Pertambahan suhu wadah dianggap linier terhadap pertambahan waktu.

\section{METODE PENELITIAN}

Langkah-langkah yang dilakukan dalam penelitian ini yaitu :

a. Memulai penelitian.

b. Melakukan tinjauan pustaka berupa water cooker.

c. Menentukan model aliran panas pemanas air elektrik.

d. Melakukan percobaan.

e. Menentukan kalor yang tersimpan dalam komponen wadah.

f. Menentukan waktu efektif mematikan pemanas air elektrik dengan melakukan pengamatan secara analitik.

g. Menyimpulkan hasil penelitian.

h. Selesai.

\section{HASIL DAN PEMBAHASAN}

\subsection{Hasil penelitian}

\subsubsection{Skema Aliran Kalor Pemanas Air Elektrik}

Pada saat memasak air dengan menggunakan pemanas air elektrik, mula-mula suhu wadah dan suhu air yang ada didalamnya adalah dianggap sama. Seiring 
dengan pertambahan waktu, baik suhu air maupun suhu wadah akan meningkat. Namun demikian, mengingat daya hantar panas logam lebih tinggi dari daya hantar panas air, suhu wadah akan senantiasa lebih tinggi dibandingkan dengan suhu air seiring dengan pertambahan waktu. Dengan demikian, terdapat kondisi dimana suhu air masih di bawah titik didih air sedangkan wadah sudah berada diatas titik didih air. Perbedaan suhu wadah dan suhu air mengakibatkan perbedaan kalor yag tersimpan pada wadah dan kalor yang tersimpan dalam air. Dengan demikian akan terjadi perpindahan kalor dari wadah yang memiliki suhu lebih tinggi ke air yang memiliki suhu lebih rendah.

Aliran kalor dari wadah ke air dapat dimanfaatkan untuk menaikkan suhu air sampai mencapai titik didihnya. Misalkan $\mathrm{t}^{*}$ adalah waktu dimana kalor yang tersimpan pada wadah dapat dialirkan ke air sedemikian hingga suhu air dapat meningkat sampai mencapai titik didih air. Pandang $0 \leq t \leq t^{*}$ sebagai fase I dan $\mathrm{t}>t^{*}$ disebut sebagai fase II. Misalkan pula $\mathrm{T}_{\mathrm{w}}(\mathrm{t})$ dan $\mathrm{T}_{\mathrm{a}}(\mathrm{t})$ secara berturut-turut menyatakan suhu wadah dan suhu air pada saat t. Skema aliran panas pada wadah dan air di kedua fase digambarkan sebagai berikut :

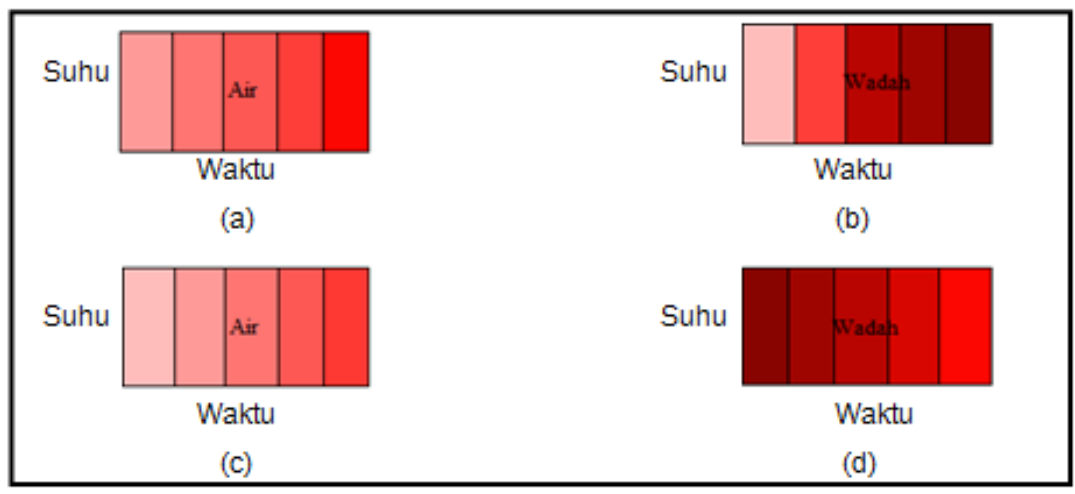

Gambar 1: Skema aliran kalor pada : (a) Wadah Dalam Fase I

(b) Wadah Dalam Fase II

(c) Air Dalam Fase I

(d) Air Dalam Fase II

Gambar 1 memperlihatkan bahwa pada fase I, suhu wadah maupun air akan meningkat seiring pertambahan waktu dengan suhu wadah senantiasa lebih tinggi dari suhu air. Sedangkan pada fase II suhu wadah menurun seiring pertambahan waktu sampai dicapai kondisi suhu wadah sangat dekat dengan suhu air yang semakin meningkat. Suhu terendah yang membuat suhu wadah dan air bersama-sama mencapai titik didih disebut sebagai waktu efektif $\left(t^{*}\right)$. 


\subsubsection{Data Pengukuran Suhu Air}

Untuk dapat menentukan waktu efektif $t^{*}$, terlebih dahulu dilakukan pengukuran langsung dari hasil penelitian mengukur suhu air yang dipanaskan dengan menggunakan pemanas air elektrik (water cooker) sampai mendidih. Pengukuran suhu tersebut dilakukan setiap 1 menit untuk massa air 750 gram sehingga diperoleh data sebagai berikut :

Tabel 1 : Data Pengukuran Suhu Air $\left({ }^{\circ} \mathrm{C}\right)$ pada saat waktu $\mathrm{t}$ (menit)

\begin{tabular}{|c|c|}
\hline Waktu (t) dalam Menit & Suhu $(T)$ dalam Celsius \\
\hline 0 & 27 \\
\hline 1 & 29 \\
\hline 2 & 32 \\
\hline 3 & 37 \\
\hline 4 & 44 \\
\hline 5 & 49 \\
\hline 6 & 55 \\
\hline 7 & 60 \\
\hline 8 & 64 \\
\hline 9 & 68 \\
\hline 10 & 71 \\
\hline 11 & 74 \\
\hline 12 & 78 \\
\hline 13 & 81 \\
\hline 14 & 82 \\
\hline 15 & 84 \\
\hline 16 & 86 \\
\hline 17 & 87 \\
\hline 18 & 88 \\
\hline 19 & 89 \\
\hline 20 & 89 \\
\hline 21 & 89 \\
\hline 22 & 91 \\
\hline 23 & 91 \\
\hline 24 & 91 \\
\hline 25 & 92 \\
\hline 26 & 93 \\
\hline 27 & 94 \\
\hline 28 & 94 \\
\hline 29 & 94 \\
\hline 30 & 94 \\
\hline 31 & 94 \\
\hline 32 & 94 \\
\hline 33 & 95 \\
\hline 34 & 95 \\
\hline
\end{tabular}




\begin{tabular}{|l|l|}
\hline 35 & 95 \\
\hline 36 & 95 \\
\hline 37 & 95 \\
\hline 38 & 95 \\
\hline 39 & 95 \\
\hline
\end{tabular}

Pada tabel 1 menunjukkan bahwa suhu air mula-mula adalah $27^{\circ} \mathrm{C}$ kemudian dipanaskan dengan menggunakan pemanas air elektrik dengan daya 2200 watt dalam setiap menit mengalami penaikkan suhu. Pada menit pertama sampai menit ke-15 suhu naik dengan cepat, namun pada menit berikutnya suhu naik dengan lambat dan pada menit ke-19 sampai menit ke-21 suhu berjalan kostan di titik $89^{\circ} \mathrm{C}$. Begitupun dimenit-menit selanjutnya sampai menit ke-33 suhu konstan di titik $95^{\circ} \mathrm{C}$ sampai menit ke-39.

\subsubsection{Menentukan Kurva Pertambahan Air Terhadap Waktu}

Data pengukuran suhu air terhadap waktu pada tabel 1 memberikan kurva suhu air terhadap waktu pada gambar 2 sebagai berikut :

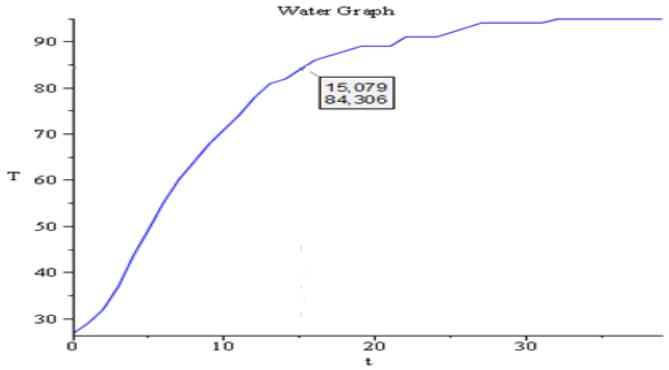

Gambar 2 : Kurva pertambahan suhu air terhadap waktu

\subsubsection{Menentukan Waktu Efektif}

Melalui kurva tersebut dapat ditentukan lokasi terjadinya titik balik pada saat $t=t^{*}=15.079$ dengan mengunakan aplikasi program maple. Titik balik tersebut merupakan lokasi dimana laju peningkatan suhu sudah negatif. Dengan peningkatan suhu yang makin kecil kalor yang tersimpan tidak lagi cukup untuk meningkatkan suhu air sampai mencapai titik didih.

\subsubsection{Menentukan Persamaan Suhu Wadah Terhadap Waktu Pada Fase I}

Dengan asumsi pertumbuhan suhu wadah adalah linier terhadap waktu maka dapat ditentukan persamaan linier yang mempresentasikannya sebagai berikut :

$T_{w}=a * t+b$ 
Dengan suhu awal wadah $27^{\circ} \mathrm{C}$, dapat diperoleh, nilai b yaitu :

$$
\begin{aligned}
& T_{0}=a * t_{0}+b \\
& 27=a * 0+b \\
& b=27
\end{aligned}
$$

Suhu wadah mencapai $T_{w}=109.606^{\circ} \mathrm{C}$ pada saat $t=15.079$ menit sehingga dengan mensubstitusikan $b=27$ ke persamaan (3) diperoleh :

$$
\begin{aligned}
& T=a * t+b \\
& 109.606=a * 15.079+27 \\
& a=\frac{82.606}{15}
\end{aligned}
$$

Dengan mensubstitusikan nilai $a=\frac{82.606}{15}$ dan $b=27$ ke persamaan (3) memberikan persamaan linier $\frac{82.606}{15} t+27$ yang mempresentasikan kurva pertambahan suhu wadah $T_{w}$ terhadap waktu t. Persamaan tersebut digambarkan sebagai berikut :

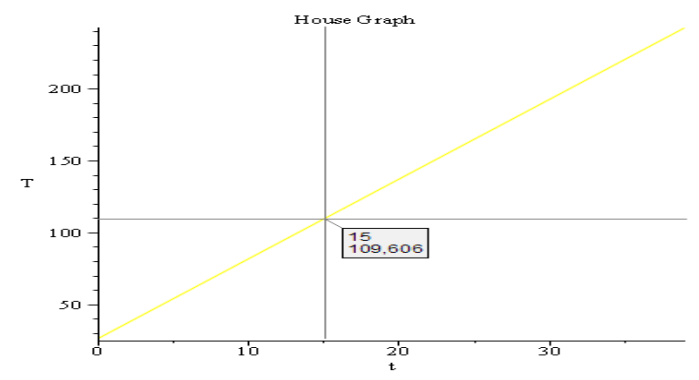

Gambar 3 : Kurva pertambahan suhu wadah $T_{w}$ terhadap waktu

Pada gambar 3 menunjukkan bahwa suhu komponen wadah mula-mula adalah $27^{\circ} \mathrm{C}$ kemudian dipanaskan dengan menggunakan pemanas air elektrik dengan daya 2200 watt dalam setiap menit mengalami penaikan suhu. Dari menit pertama dan seterusnya suhu naik dengan cepat dan membentuk kurva linier. Pada saat 15.079 menit, suhu komponen wadah sebesar $109,606^{\circ} \mathrm{C}$, dari kurva (2) dan (3) terdapat perbedaan suhu sebesar $25,3^{\circ} \mathrm{C}$ yang mencerminkan transfer suhu dari komponen wadah ke komponen air.

\subsubsection{Menentukan Kalor Yang Tersimpan Pada Wadah dan Air}

Kalor yang terdapat pada komponen air dengan suhu awal $27^{\circ} \mathrm{C}$, massa air 750 gram, massa jenis air sebesar $1 \mathrm{kal} / \mathrm{gr}^{\circ} \mathrm{C}$ dan suhu akhir air $84.306^{\circ} \mathrm{C}$ dengan menggunakan persamaan sebagai berikut :

$$
\begin{aligned}
& Q_{1}=m_{1} * c_{1} * \Delta T_{1} \\
& Q_{1}=750 \mathrm{gr} * 1 \frac{\mathrm{kal}}{\mathrm{gr}^{\circ} \mathrm{C}} *\left(84.306^{\circ} \mathrm{C}-27^{\circ} \mathrm{C}\right) \\
& Q_{1}=42979.5 \mathrm{kal}
\end{aligned}
$$


Selanjutnya dapat ditentukan pula jumlah kalor yang terdapat pada komponen wadah dengan suhu awal $27^{\circ} \mathrm{C}$, massa wadah 3000 gram, massa jenis wadah sebesar $0.21 \mathrm{kal} / \mathrm{gr}^{\circ} \mathrm{C}$ dan suhu akhir wadah sebesar $109.606^{\circ} \mathrm{C}$ yaitu dengan menggunakan persamaan sebagai berikut:

$Q_{2}=m_{2} * c_{2} * \Delta T_{2}$

$Q_{2}=3000 \mathrm{gr} * 0.21 \frac{\mathrm{kal}}{\mathrm{gr}^{\circ} \mathrm{C}} *\left(109.606^{\circ} \mathrm{C}-27^{\circ} \mathrm{C}\right)$

$Q_{2}=52041.78 \mathrm{kal}$

Hasil tersebut memperlihatkan bahwa kalor yang terdapat pada komponen wadah lebih besar dari kalor yang terdapat pada komponen air sehingga akan terjadi aliran kalor dari komponen wadah ke komponen air.

\subsubsection{Menentukan Persamaan Suhu Wadah Terhadap Waktu Pada Fase II}

Kurva suhu wadah terhadap waktu pada fase II ditentukan melalui persamaan eksponensial sebagai berikut :

$y\left(T_{w}\right) C_{1}=e^{-t}+C_{2}$

Dari gambar 2 diperoleh waktu yang tepat untuk mematikan suhu air yaitu saat $\mathrm{t}=15$ dan $C_{2}=95$, dari gambar 3 dengan waktu yang sama diperoleh suhu wadah ( $T_{w}$ ) sebesar $109,606^{\circ} \mathrm{C}$, sehingga melalui data tersebut dapat dihasilkan persamaan eksponensial sebagai berikut :

$y\left(T_{w}\right)=e^{-t+17,681}+95$

Persamaan tersebut digambarkan sebagai berikut :

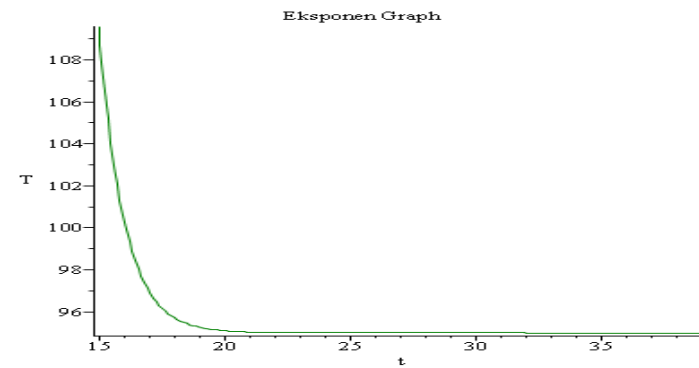

Gambar 4 : Kuva penurunan suhu wadah $\mathrm{T}_{\mathrm{w}}$ terhadap waktu

Pada gambar 4 menunjukkan bahwa suhu komponen wadah mula-mula adalah $109,606^{\circ} \mathrm{C}$ kemudian turun secara eksponensial sampai $95^{\circ} \mathrm{C}$. Hal tersebut memperlihatkan aliran kalor dari komponen wadah yang ditransfer ke komponen air 
sehingga suhu pada komponen wadah turun sebesar $25,3^{\circ} \mathrm{C}$. Penurunan secara monoton tersebut akan berlangsung sampai tercapai suhu titik didih air.

\subsubsection{Kurva Gabungan Suhu Air Dan Wadah Terhadap Waktu Pada Fase II}

Kurva gabungan suhu air dan wadah terhadap waktu pada fase II adalah sebagai berikut :

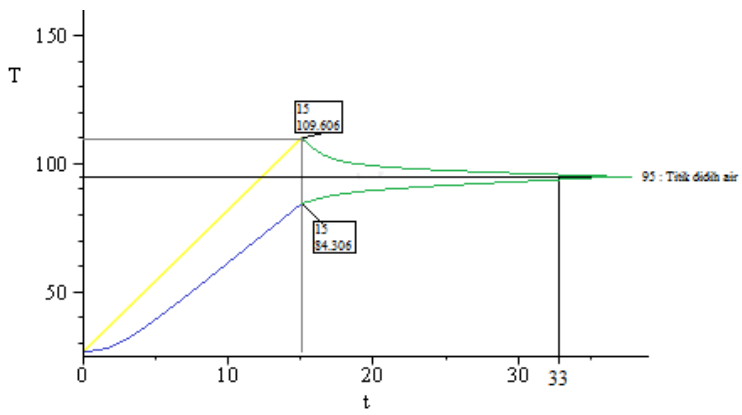

Gambar 5 : Kurva gabungan wadah dan air terhadap waktu pada fase II

Gambar 5 menunjukkan gabungan antara gambar 2, 3 dan 4 bahwa yang menggambarkan proses peningkatan suhu wadah dan suhu air pada fase I serta peningkatan suhu air dan penurunan suhu wadah terhadap waktu. Pada saat pemanas air dimatikan, yaitu $t^{*}=15$, suhu wadah mencapai $109,606^{\circ} \mathrm{C}$. Selama 18 menit kemudian suhu wadah tersebut turun secara eksponensial mengikuti persamaan (5) hingga mencapai titik didih air pada suhu $95^{\circ} \mathrm{C}$. Suhu komponen air pada saat $t^{*}=$ 15 adalah $84,306^{\circ} \mathrm{C}$, kemudian bergerak naik mengikuti persamaan (1) hingga mencapai titik didihnya pada suhu $95^{\circ} \mathrm{C}$. Hal tersebut dikarenakan kelebihan kalor pada komponen wadah ditransfer ke komponen air.

\subsection{Pembahasan}

Hasil yang diperoleh dari data pada Tabel 1 memperlihatkan bahwa suhu komponen air meningkat dengan cepat dalam 18 menit pertama, kemudian peningkatannya mulai melambat pada menit-menit berikutnya hingga mencapai titik didihnya. Pada Gambar 3 dapat dilihat suhu komponen wadah meningkat secara linier terhadap waktu. Pada saat $t^{*}=15$ suhu komponen wadah mencapai $109.606^{\circ} \mathrm{C}$. Pada Gambar 4 memperlihatkan kelebihan kalor yang tersimpan pada komponen wadah akan dialirkan ke komponen air sehingga kurva linier pada Gambar 3 tidak lagi dipenuhi untuk $t>t^{*}$. Suhu komponen wadah turun secara eksponensial hingga mencapai titik didih yaitu $95^{\circ} \mathrm{C}$. Pada Gambar 5 diperlihatkan aliran kalor dari komponen wadah ke komponen air digunakan untuk menaikkan suhu komponen air 
hingga mencapai titik didih yaitu $95^{\circ} \mathrm{C}$. Suhu pada komponen air dan komponen wadah akan mencapai titik temu pada titik didih air $95^{\circ} \mathrm{C}$.

\section{KESIMPULAN}

Berdasarkan penelitian yang telah dilakukan dapat disimpulkan bahwa untuk menentukan waktu yang efektif untuk mematikan pemanas air elektrik agar penggunaan energi listrik lebih efisien dilakukan dengan cara menentukan lokasi terjadinya titik balik pada pencocokan kurva data pengukuran suhu air $\left({ }^{\circ} \mathrm{C}\right)$ pada saat waktu $\mathrm{t}$ (menit). Titik balik tersebut, yaitu $t^{*}=15$ menit, adalah waktu efektif untuk mematikan water cooker (pemanas air elektrik). Suhu komponen air pada saat $\mathrm{t}^{*}$ adalah $84,306^{\circ} \mathrm{C}$ dan suhu komponen wadah sebesar $109,606^{\circ} \mathrm{C}$. Dengan selisih perbedaan kalor sebesar 9069,28 kal, terjadi aliran kalor dari komponen wadah ke komponen air sehingga suhu komponen wadah akan turun mencapai titik didih $95^{\circ} \mathrm{C}$ dan suhu komponen air akan meningkat sampai titik didih $95^{\circ} \mathrm{C}$.

\section{DAFTAR PUSTAKA}

[1]. Frits, 2013. Thermos in the workshop on mathematical modelling of physical phenomena. Palu: FMIPA Universitas Tadulako.

[2]. Giancoli, C., Douglas, 2001, Fisika Jilid 1 Edisi Kelima, Jakarta : Erlangga. 